\title{
Innovation by demand? An introduction
}

Andrew McMeekin, Ken Green, Mark Tomlinson and Vivien Walsh

\section{Sociologists and economists on consumption and demand}

The structure and regulation of consumption and demand have recently become of great interest to sociologists and economists alike, 'consumption' being the focus of sociological accounts, whilst 'demand' has been the preserve of economists' analyses. At the same time, there is growing interest, especially among economists, in trying to understand the patterns and drivers of technological innovation. The connection between consumption/demand and innovation suggests a number of interesting questions. How do macrosocial shifts influence patterns of consumption? How do firms and other organisations structure markets and create demand? How do perceptions of demand influence the innovative activities of firms? How do consumers respond to the innovative offerings of firms?

In 1999 the Centre for Research in Innovation and Competition (at Manchester University and UMIST) ran an international workshop to explore these themes. The primary aim of the workshop was to bring together sociologists and economists to look at how they study the role of demand and consumption in the innovation process. There have been few attempts to find points of contact between the diverse approaches. So the focus of the workshop was on identifying differences and complementarities in approach, with a view to finding possible common ground and new interdisciplinary research directions. This book presents some of the papers from the workshop and others of CRIC researchers that explore the same theme.

The first two chapters set the scene for the whole volume. They offer broad conceptual overviews of ways that the sociological and economics literatures address issues of innovation, demand and consumption. Alan Warde, in Chapter 2, reviews the sociological literature on consumption, focusing in particular on research that offers alternative or complementary views to the concepts of 'conspicuous consumption' and individual choice, which has dominated much work in this area. From this, he proposes a research agenda for examining everyday consumption, that is, consumption that is unremarkable, bound by habit and routine, and which takes place in the context of social networks and institutions, by which it is also constrained. As he points 
out, many things can be consumed only within the boundaries of practices that are social, cumulative and governed by convention. Furthermore, his approach is sufficiently embracing to include public and institutional consumption, as well as individual consumption. It also allows consideration of the downstream generation of demand for infrastructural and complementary products, and hence of environmental sustainability in consumption.

In Chapter 3, Peter Swann offers a companion piece to Alan Warde's. $\mathrm{He}$ examines the way in which economists have understood demand. Mainstream, neoclassical or 'standard' economists, he maintains, focus on demand as a process in which selections are made among commodities, typically assuming 'rational' and profit-maximising behaviour on the part of the actors making the selections. On the other hand, sociology offers an understanding of the personal appropriation of goods and services via multiple and social uses, and the consumption of output from non-market as well as market sources. Swann surveys the major contributors to the economics of consumption: in addition to the mainstream (the econometric paradigm, Gorman, Deaton and Muellbauer) he considers the contributions of 'the giants' (Smith, Senior, Marx, Marshall, Ruskin, Keynes, Veblen, Mill and Jevons), and 'the travellers' (Scitovsky, Galbraith, Earl, Arthur Lewis). He concludes that there is more to the economics of consumption than the mainstream economists' paradigm of utility maximisation. Indeed, he argues, economists should look to other disciplines for inspiration. Evolutionary economics in particular has taken on board some of the preoccupations of sociologists in its concept of the selection environment, in which non-market as well as market factors play a significant role in the selection process. To this end, Swann lastly reviews the contribution from the 'Revival', or recent economic writings building on insights from other social sciences (e.g. Becker, Akerlof, Cowan, van Weizacker and Swann himself).

\section{Different perspectives on consumption and demand}

The next two chapters offer different approaches to the economics of demand and innovation through an evolutionary framework.

In previous papers, Paolo Saviotti has studied the relation between the composition of the economic system and its capacity to generate long-run economic development. Saviotti has concluded that an important concept is 'variety growth', which is a requirement for the continuation of long-run economic development and leads to the creation of new sectors. The role that variety can play in economic development has important implications for economic theory, including the theory of demand. Some of the assumptions that are made in demand theory are appropriate only for a static, shortrun analysis. They need to be modified for the analysis of long-run development. Moreover, the evolution of demand can represent a bottleneck in economic development. If the economic system is changing continuously, preferences cannot be taken as given; the formation of preference has to become a 
legitimate subject for economics. Saviotti offers a theory of wants and preferences which assumes that consumers will start consuming a given good/service only when they achieve a critical income. In order for variety to increase in the course of economic development, new goods/services must be 'added' to existing ones. Saviotti's analytical treatment offers some insight into the conditions under which variety can contribute to economic development.

Wilhelm Ruprecht, in Chapter 5, offers a different slant on an understanding of demand by reviewing how consumption fits into 'evolutionary' models of economic development. He addresses two questions. As Saviotti argues, when only the supply side of growth is looked at in the presence of market satiation, both product and process innovations are complementary preconditions for sustainable economic growth. Without the introduction of new products, an increasing share of resources would remain unemployed. Neoclassical theory finds thinking about the case of consumer goods novelty particularly difficult, because the adoption of only a subset of new commodities can only be reconciled with an assumption of given preferences. Thus a critical question is how preferences for new commodities come into being, how new goods are adopted. Ruprecht explores the thinking on this topic of a number of writers, from a range of disciplines, including neoclassical economists, psychologists and socio-biologists. He concludes that biological and psychological perspectives, fitted into frameworks of evolutionary economics, have much to tell us about the formation of preferences, and economists should be open to such diverse approaches if they are to understand the relationship between innovation and demand.

Chapter 6, by Mark Tomlinson and Andrew McMeekin, looks at the routine nature of food consumption. The existence of consumption routines is particularly significant for those interested in the diffusion of innovative consumer products. The implication is that existing routines need to be modified or broken for innovations to succeed. This is reflected in practice, as advertisers and market research attempt both to reinforce routine consumption behaviour and to bend it in new directions. This they frequently do through activities that are based on stratified populations of consumers. Consequently, product ranges are designed so that a hierarchy of products are offered to different social groups. Advertisements too are created and presented in a manner to make clear the social significance of consuming a certain good. The chapter examines the dynamic nature of socially constituted consumption routines. The authors define a consumption routine as an executable capability for repeated consumption that has been learned or acquired by groups of consumers in response to social pressures or contexts. This notion of routine is taken from evolutionary economics, but is modified to take account of the sociology of consumption, in an explicit attempt to combine insights from both economic and sociological approaches.

The chapter operationalises the concept of socially based consumption routines by conducting statistical analysis of national data sets that include data on food consumption. Different foods are found to hold different social 
significance. Both persistent social class and social mobility are significant determinants of changing routines, but they operate in different ways for different foods.

Chapter 7, by Virág Molnár and Michèle Lamont, analyses how black Americans use consumption to express collective identity. Two processes of 'group identification' and 'social categorisation' are explored through interviews conducted with black marketing experts who specialise in the AfricanAmerican market place. These interviews provide a rich data source, giving insights into the meaning of consumption for blacks. The marketing experts are viewed both as individual consumers and as members of an occupational group that is built on increasing the importance of consumption in creating individual social identities. They argue that for African-Americans the formation of collective identity is centred on defining their place in US society, finding ways through consumption behaviour to demonstrate social membership. Furthermore, the concepts of group identification and social categorisation improve our understanding of the meaning of consumption for this group. The role of the marketing specialists is found to have a crucial role in defining what it means to belong in black society in terms of defining the space of black consumption itself and also in shaping the wider public's perceptions of blacks through intermediaries such as the advertising industry.

Leslie Haddon, in Chapter 10, looks at the involvement of consumers in innovation. Two case studies are presented which detail a number of interesting issues regarding ways that consumers become involved in new product development or longer-term R\&D in the Information and Communication Technology (ICT) sector. In some cases, consumers have been actively involved during new product development. Much more common was later involvement, in the form of product testing and evaluation of interfaces. In other cases, consumers are 'represented' through perceptions of consumer behaviour built up by designers and product managers. There are also differences with respect to the formality of these arrangements; in some cases, dedicated units have been established by (usually larger) firms to achieve consumer involvement.

Despite there being activities geared towards integrating consumers (or representations of consumers) into innovation processes, Haddon finds that the impact is often limited. For what are perceived as more radical innovations, consumer input often takes place relatively late in the whole process, although in some firms there is now more involvement of consumers at the conceptual stages. Given that many product ideas stem from awareness of technological possibilities, consumers' feedback is more usually in the form of reaction to product proposals rather than generating them. Even in more incremental new product development projects, the information that is collected about consumers can become marginalised relative to other considerations. In short, Haddon shows that there is evidence of firms attempting to learn about consumers as input to their innovation processes, but that to date these efforts are rather underdeveloped. 
Vivien Walsh, Carole Cohen and Albert Richards, in Chapter 11, also focus on users and how their needs may be incorporated (successfully or otherwise) in the design of high-tech products. After first surveying the evolution of user orientation, user-friendliness, user-centred design and human-machine interaction in the ICT industry, they report an ethnographic study of telecom product design. They found that the job of the design team in a high-tech industry where firms collaborate was just as likely to be the design of the organisational arrangements for the development and delivery of new products and services as the design of the products and services themselves. Design as an activity links many of the functions in the business enterprise and its environment; building such links is an essential part of the design and innovation process. The authors found that usability testing took a very particular form in which to pay attention to users' needs: on the whole the trials acted as a confirmation and justification of decisions more or less firmly made, rather than being a more open-ended exercise. But, as a result, some unexpected findings were made that either had to be taken into account with downstream consequences, or could not be taken into account, and had to be incorporated into a future product design. The study also provided some interesting insights into the way in which engineer-designers take 'situated' actions, that is, actions which have to be adapted to the unforeseeable contingencies of particular situations.

The final three chapters look at demand-innovation relations within matrices or chains of producers and users and other actors (these differ in each of the cases).

Bonnie Erickson (Chapter 8) argues that, for example, in service industries such as security, demand for a service is inseparable from the demand for the kind of people seen as suitable for providing the service. One important example is women providing services in sectors that were once dominated by men. (There has been a large literature on gender segregation in social science.) The massive movement of women into paid employment can be considered as a significant innovation, involving many people and many industries. Erickson traces such variability of innovation to the complexity of a 'relational matrix' within which innovation is embedded. The matrix includes several kinds of key actors such as employers, service providers, potential employees, clients and targets to whom service work is directed on behalf of clients.

Innovation varies with both real and perceived gender distributions and what is termed gender 'homophily' within the matrix. Gender distributions either limit or enable innovations. For instance, employers can use female labour in innovative ways only to the extent that they have female service providers on hand or can recruit them from potential employees as well taking into account the appropriateness of gendered roles in the market. An analysis of the Canadian security industry is used to explore these issues using various data sources.

In Chapter 9, Ken Green, Barbara Morton and Steve New are interested in whether the use of 'consumer' pressure in improving the environmental 
performance of companies, a tactic long advocated by environmentalists, stands critical scrutiny. An important aspect of this criticism is to examine the concept of 'the consumer'. The traditional image of who is meant by 'the consumer' is inadequate, they argue, both in economics and sociology and as an agent of environmental change. Efforts to 'green' the economy require an understanding of corporations and public organisations, as well as individuals, as consumers. Their chapter examines the deficiencies of traditional definitions of consumption and sets out the arguments for treating corporate organisations as consumers, and develops a framework for examining the differences and similarities between the two categories. Using the concept of the 'supply chain', they suggest that more attention needs to be paid to the mechanisms, both between and within firms and organisations, through which they engage in buying and selling. Such mechanisms are the organisation sites for the articulation of 'demand' and 'consumption'. Their study should add both to theories of how innovation takes place and to a better understanding of the best methods of intervention for governments and activists who wish to improve environmental performance.

In Chapter 12, Mark Harvey argues for the need to build an economic sociology/political economy of demand that goes from micro-individual through to macro-structural features. To achieve this, an 'instituted economic process' approach to the study of demand and innovation is developed to account for processes of institutionalisation and deinstitutionalisation. Within this framework, the concept of a 'production-distribution-retail-consumption' configuration is seen as shaping innovation. The empirical investigations of this chapter involve analysis of how retail markets link demand with supply, and how that link is a structured one: the interface facing both ways. Harvey argues that markets are more than black boxes through which products pass, and that they are more than spaces for exchange, thus getting away from the dualism of supply and demand.

He explores three empirical cases. The first involves the near disappearance of wholesale markets (in this case, New Covent Garden) for fresh fruit and vegetables to retail markets, and the particular questions raised in terms of range and quality of products that flow through them. The second deals with an equally significant reconfiguration of the retail-distributionproduction configuration reflected in the emergence of supermarket ownlabel products. The third raises the question of how the organisation of retail markets, and their transformation, alters the way demand is instituted between end consumer and retailer. Circuits or spirals of supply and demand are more 'elemental' than either of these two moments taken separately. So the analysis needs to be one of changing and comparative configurations of these circuits and spirals. The separation of demand from supply, rather than either term taken separately, is the fundamental object of analysis. 


\section{Some commentary}

The chapters in this book are diverse in approach, method and empirical object of study. Variously drawing on economic and sociological approaches, they take firms or consumers or both as objects of study; in some the analysis is micro-oriented, in others a macro-structural explanation is preferred. All the chapters reveal the limitations of neoclassical economics, sometimes explicitly, sometimes not, by arguing that consumption (and purchase) cannot be assumed to be governed by utility maximisation or 'Olympian rationality' as in the orthodox neoclassical economics tradition. They also argue that it is the dynamic properties of consumption and demand in relation to innovation that are of interest (in contrast to notions of static equilibrium). Further, consumers cannot be seen to have immanent, a priori defined preferences, a point made both by economists (Saviotti, Ruprecht) and sociologists.

There are also limitations to sociologists' accounts of consumption as they have developed over the last ten years. Though such accounts see consumption as 'socially constructed', they limit what is included in the 'social' sphere, especially omitting or underplaying the importance of incomes and prices in determining what is bought and consumed. In addition, they rarely include the firm as a unit of analysis, losing any understanding of one of the main sources of innovation which, to greater or lesser extents, sets the limits to what consumption can take place. This lack especially rules out any analysis of consumption between firms in business-to-business relations. In addition, sociologists' accounts have focused so far on a narrow range of products, linked with notions of fashion and overt displays of 'lifestyle'. Most of these are innovative only in their form, with the technologies that underpin them relatively unchanging. However, there is a huge range of other purchases (e.g. consumer durables) and these are much more susceptible to technological innovations. Taken together, these gaps mean that sociologists of consumption only weakly analyse the relation between consumption and production in firms, and the ways in which the development and design of new products require interaction between (imagined) consumers and the innovators and designers. (See Chapter 10 by Haddon and Chapter 11 by Walsh et al. for elaborations of this.)

So the economics-dominated accounts view the consumers as individuals, and examine consumers' propensity to consume as determined by incomes, the price of products and evolving preferences. In contrast, the more sociological accounts are based on a fundamental rejection of this methodological individualism and consider consumption as a collective activity, rooted in social structures. They put the emphasis, therefore, on the social group in a social hierarchy, acting in relation to other social groups: competition, distinction, association and aspiration. Consumption is seen to be contingent on social factors of gender, race and occupational class. In some of the studies, the behaviour of consumers is studied as autonomous to the actions of firms. In other cases, it is the relationship between consumers and firms 
that is of interest (and in one of the studies, the 'consumers' in question are actually firms).

The 'mainstream' innovation literature has long stressed the importance of demand in understanding innovation processes. However, there has been comparatively little analysis of these connections, with the majority of studies focusing on the co-ordination and management of the supply side. This neglect perhaps stems from the work of Joseph Schumpeter, an economist of technological change, who wrote several defining texts in the twentieth century. In his analysis, innovation was treated as a major driving force of economic growth, emanating from the risk-taking investments of 'heroic' entrepreneurs, and later by large companies. The motivation to invest was based on a perceived technological opportunity. In this model, final consumers were simply seen as the passive recipients of new products.

In the middle of the century, a body of empirical work emerged to counter this 'technology push' model. The proponents of the 'demand pull' position argued that technological innovation, like the majority of other economic activities, was driven by responses to market signals. These alternative positions fuelled a number of empirical studies seeking to demonstrate the relative importance of technological opportunity and demand factors in determining the rate and direction of innovation. The debates culminated with an influential article by Mowery and Rosenberg (1979), who argued strongly against the demand-pull position. In particular, they questioned what was meant by demand in relation to needs or market signals. There has been very little attention to this issue since.

The user-producer approach proposed by Lundvall (1988) is one explicit attempt to resolve the disputes:

One of the classic disputes in innovation theory refers to the role of demand and supply in determining the rate and direction of the process of innovation. The user-producer approach puts this question in a new perspective. On the one hand, it demonstrates that demand does play an important role in the process of innovation. On the other hand, it puts the emphasis more upon the quality of demand than upon demand as a quantitative variable. (Lundvall, 1988, p. 357)

However, despite the important contribution of this work, the emphasis has been placed predominantly on interactions between firms as producers and users. Final consumers have rarely been considered in the mainstream innovation literature.

The main exception is the diffusion of innovation literature. However, these studies have offered oversimplified accounts by treating populations of potential adopters as being socially homogeneous. One of the most well known models of adoption distinguishes between innovative adopters, the early majority, the late majority and laggards (Rogers, 1962). In other words, they are simply defined by their propensity to adopt. The explanation is typically a combination of income and a notion of motivation towards things novel. Social factors and processes have been dealt with tangentially, if at all. 
Essentially, then, the model is individualistic, with no consideration of relations between different social groups. This, we believe, is inadequate for understanding the diffusion of products in consumer markets.

We suggest that to understand better the relationships between consumption, demand and innovation we need to pay attention to the dynamic nature of final and intermediate consumption. The dynamics of interest are evident at a number of interrelated levels. First, there are changes in patterns of consumption that emerge through macro-social shifts, changing relationships between different social groups. Second, there are changes in the structure of consumption brought about by shifts in the structure of production and retailing. Third, there are changes in practices of consumption with the innovation of new goods and services. Through a combination of economic and sociological approaches, the contributions to this volume make a significant advance to understanding these processes and relationships.

\section{References}

Lundvall, B-Å. (1988), 'Innovation as an interactive process: from user-producer interaction to the national systems of innovation', in Dosi, G., et al. (eds), Technical Change and Economic Theory, London, Pinter.

Mowery, D., and Rosenberg, N. (1979), 'The influence of market demand upon innovation: a critical review of some recent empirical studies', Research Policy, 8, 102-53.

Rogers, E. (1962), The Diffusion of Innovations, New York, Free Press. 